\title{
Conceptualizing and Operationalizing Subdimensions of Employees' Cognitive and Emotional Trust in Supervisor
}

\author{
Pei LIU ${ }^{1, a}$, Wan-Fen GUO ${ }^{2, b, *}$ \\ ${ }^{1}$ North China University of Water Resources and Electric Power, Zhengzhou 450046, CHINA \\ ${ }^{2}$ The International College, Xiamen University, Xiamen 361102, Fujian, CHINA \\ 1'delicatemechanics@163.com, ²guowanfen@xmu.edu.cn. *Corresponding author
}

Keywords: Cognitive \& Emotional Trust, Social Exchange Theory, Employee-Supervisor Relationship, Subdimensional Scales, Each Subdimension's Unique Influencing Process.

\begin{abstract}
Our first purpose is to develop subdimensional models of employees' cognitive \& emotional trust (CT \& ET) in supervisor, which can explain each subdimension's unique influencing process at concrete and specific level. Based on trust and social exchange literature, we hypothesized that CT in supervisor can be broken down into three subdimensions (a) competence, (b) benevolence, and (c) integrity; and ET in supervisor can be broken down into three subdimensions (d) emotional linkage, (e) identification, and (f) depending willingness. These two subdimensional models were supported by a series of factor analysis, using Chinese student and Japanese employee sample. Our second purpose is to develop and validate scales of these six subdimensions (CTS-15 \& ETS-15 in Supervisor), which can be distinguishable enough to reliably capture their unique relations with other constructs. Reliability, factorial validity, convergent \& discriminant validity, and criterion validity of CTS-15 \& ETS-15 in Supervisor were established by Chinese student and Japanese employee sample.
\end{abstract}

\section{Introduction}

The crucial roles of two ongoing interpersonal trusts — cognitive and emotional trust (CT \& ET) —in developing social exchange relationship (SER) have received increasing attention in a variety of disciplines. The multidisciplinary perspective gives rise to different research concerns that are at different level of abstraction and generality. At abstract level, social psychologists focus on building general theories about the underlying social psychological mechanisms which can explain how CT \& ET play different roles in sustaining SER [1]. Such general theories are useful in deducing, comparing, and integrating middle-range theories across different application fields such as employees-supervisor context, consumer-salesperson context, patient-doctor/nurse context, etc. At middle level, for example, organizational behavior researchers are interested in deducing middle-range theories about the mediating organizational behavioral mechanisms, which can explain and predict the different effects of employees' CT \& ET in supervisor upon their work-related attitudes and behaviors [2]. Although these middle-range theories can be applicable to organizational setting across different cultures, they usually have no enough information to develop concrete trusting skills in managerial practice. At concrete level, for developing trusting skills, managers require to break down the underlying organizational behavioral mechanisms into specific mediating components in order to identify distinct concrete influencing processes, which may be moderated by cultural or situational factors. Hence, there is a strong need to systematically develop a hierarchical conceptual framework consisting of abstract concepts (CT \& ET), middle-range constructs (e.g., employee's CT \& ET in supervisor, customer's CT \& ET in salesperson, patient's CT \& ET in doctor/nurse ), and concrete subdimensions of each middle-range construct. Additionally, for each application field, there is also a need to develop second-order scales composed of middle-range constructs and their concrete subdimensions. In the field of organizational behavior, existing research is increasingly converging on the conceptualization of employee's CT \& ET in supervisor [2], and some valid middle-range scales have been developed [3]. However, the subdimensions of ET in 
supervisor are still unclear. Therefore, our purposes are (1) to conceptualize the subdimensions of CT \& ET in supervisor; (2) to develop and valid subdimensional scales-CTS-15 \& ETS-15 in Supervisor.

\section{Hierarchical Conceptual Framework}

\section{Abstract Concepts}

SER between Trustor and Trustee. In this work, we conceptualize CT \& ET on the basis of social exchange theory $[1,4,5]$. We first provide some basic terms describing SER. According to [5], SER consists of exchanging process and long-term relationship.

Exchanging process is composed of three elements. The first is resources of exchange that can fall into two categories: objective resources with general utility and subjective resource with personal happiness, consistent with extrinsic-intrinsic incentives in motivation theory. The exchanges of objective resources are often conditioned by situations, whereas the exchanges of subjective resource are usually not. The second is exchanging behaviors referring to trustor's behaviors that exchange objective and subjective resource with trustee under reciprocity principle. The third is outcomes of exchange defined as the objective resources resulting from exchanging behaviors with a time lag and uncertainty. Thus, by definition whether exchanging behaviors bring a satisfactory outcome is usually situation-dependent. We do not use the term "outcome" to refer to subjective resource because it is a kind of intrinsic happiness inherent in exchanging behaviors.

Long-term relationship can be characterized by emotional bonds, the shared interests and values, and mutual obligations and gratitude. In this work, we used the two kinds of ongoing trust to capture such relationship. CT captures trustee's traits, whereas ET catches the quality of this relationship [2].

Trust. Rousseau et al.'s cross-discipline review identified two key elements in various trust definitions: positive expectations and willingness to be vulnerable [6]. Under high-risk and high-interdependence situations, these two elements make trust still effective in bringing out trustor's risk taking behaviors. In general, CT is defined as the expectations and willingness based on the knowledge of trustee's traits, ET refers the expectations and willingness rooted in a high-quality long-term relationship with trustee [2, 3]. CT functions to secure the productivity of SER by focusing on the extrinsic utility of the exchange outcomes, from the perspective of gains and losses; whereas ET functions to build up a base of the long-term relationship by focusing on the intrinsic happiness inherent in the relationship and/or exchanging process, from the perspective of maintaining SER.

H1: In ongoing relationships interpersonal trust can be generally categorized into two different

kinds: cognitive \& emotional trust (CT \& ET).

\section{Middle-Range Constructs}

CT in Supervisor. CT in supervisor is defined as employees' outcome-oriented expectations for the supervisor's decisions/actions that will provide them with extrinsic interests. The mediating organizational behavioral mechanism underlying CT consists of following three parts. The first is objective resource-based interdependence such as the asymmetry interdependence in task \& management between employees and their supervisor in organizational setting. The second is an estimating process by which employees can use the past outcomes to estimate the supervisor's traits based on the understanding of the structure of task \& management dependence. The third is a predicting process by which employees can use the supervisor's traits to predict the future outcomes of exchange based on the understanding of the structure of task \& management dependence.

ET in Supervisor. ET in supervisor refers to employees' relationship-oriented expectations/willingness focusing on the interactions with their supervisor in which the intrinsic happiness inherent. The mediating organizational behavioral mechanism underlying ET consists of following three parts. The first is subjective resource-based interdependence such as the symmetrical interdependence of happiness in work life between employees and their supervisor. The second is a relationship building process, by which exchanging behaviors for subjective resource can build up a 
base of the long-term relationship, independently of what short-term outcomes the objective resource exchanges lead to. The third is an intrinsic-motivating process by which the intrinsic happiness inherent in the long-term relationship can motivate exchanging behaviors for subjective resource.

\section{Concrete Subdimensions of Each Middle-Range Construct}

Three Subdimensions of CT in Supervisor. We identified three most important traits in work setting-(a) competence, (b) benevolence, and (c) integrity-from prior study [7], which have distinct mediating components in the underlying organizational behavioral mechanisms. Thus, each of these three subdimensions is likely to have a unique concrete influencing process.

a) Competence refers to employees' positive expectations for the supervisor's ability-based challenges, such as planning ambitious goals and projects which can create good chances for them to grow. In organizational work system, such challenges of supervisor can cause a change in employees' potential of expertise improvement and career development, which in turn can satisfy their needs for improving expertise and achieving a successful career. Thus the key mediating component underlying competence subdimension is the potential of expertise improvement and career development.

b) Benevolence means employees' positive expectations for the personal good intention-based managerial decisions of the supervisor, such as taking into account their interests and career development. Such supervisor decisions can lead to a change in employees' probability of suffering losses due to weak position and obtaining good chance to grow, which in turn can satisfy their needs for not suffering losses and achieving a successful career. Thus, this probability is the key mediating component underlying benevolence subdimension.

c) Integrity is defined as employees' positive expectations for the universal ethics principle-based behaviors of the supervisor, such as always having the good sense to prevent troubles, and making decisions and instructing consistently so as not to put employees into confusion. Such supervisor behaviors can produce a change in employees' probability of suffering losses due to troubles, wasting time and energy, and low performance, which in turn can satisfy their needs for protecting individual rights and interests from being hurt, and not suffering losses. Thus this probability is the key mediating component underlying integrity subdimension.

H2: CT in supervisor can be broken down into three subdimensions: (a) competence, (b) benevolence, and (c) integrity.

Three Subdimensions of ET in Supervisor. We identified three key aspects of the long-term relationship - (d) emotional bonds, (e) the shared long-term interests and values, and (f) mutual obligations and gratitude-from previous literature, by specifying three important mediating components in the organizational behavioral mechanisms underlying ET in supervisor. Each subdimension is likely to have a unique concrete influencing process.

a) Emotional linkage is defined as employees' positive expectations for the supervisor's emotional bond-based behaviors, such as empathizing with them (i.e., reproducing their feelings and emotions) and then sincerely communicating with them. Such supervisor behaviors can increase the pleasure of the communication, which in turn can satisfy their needs for being emotionally linked with others. Thus, the pleasure of communication is the key mediating component underlying emotional linkage subdimension.

b) Identification is defined as employees' positive expectations for the supervisor's ingroup identity-based behaviors, such as taking their perspective (i.e., reproducing their thoughts) to grasp "what is good for their career" and then effectively supporting them. Such supervisor behaviors can strengthen the sense of belonging, which in turn can satisfy their needs for belonging to an ingroup where members have shared the long-term interests, thinking, and values. Thus, the sense of belonging is the key mediating component underlying identification subdimension.

c) Depending Willingness means employees' willingness to positively accept the risks of depending on the supervisor in order to deepen the mutual obligations and gratitude in the relationship. 
Depending willingness is based upon the positive expectations for the supervisor's helping behaviors, such as helping them both officially and privately in good faith. Such supervisor behaviors can generate employees' feelings of gratitude and/or sense of obligation to return favors, which in turn can satisfy their needs for a warm and solid relationship rich in mutual obligations and gratitude. Thus, the feelings of gratitude and/or sense of obligation are the key mediating components underlying depending willingness.

H3: ET in supervisor can be broken down into three subdimensions: (d) emotional linkage, (e) identification, and $(f)$ depending willingness.

\section{Method}

\section{Item Generation}

At step1, to generate an initial pool of items, we identified six content domains being consistent with the guidelines described above: (a) competence, (b) benevolence, (c) integrity, (d) emotional linkage, (e) identification, and (f) depending willingness. At step 2, we composed the initial version of item pool with items collecting from 17 existing trust measures, and then classified these items following content domains of each construct. At step 3, we generated some original items based on content domains of each construct. As a result, the item pool turned into a version of 94 items, which were then translated into Chinese and Japanese version separately.

\section{Content Validity}

Five Chinese managers and three Chinese management researchers evaluated Chinese version of these 94 items. Items were eliminated if, upon further consideration, (1) they described situations not common to most organizations, or (2) their contents did not correspond to the definitions, or (3) they would imply sensitive issues for Chinese organizational contexts. In this process, no item was eliminated. And then, five Japanese organizational behavior experts (three researchers and two Ph.D. students) assessed Japanese version of these 94 items using the same procedure. As a result, 6 items of (f) depending willingness domain were eliminated because they would imply sensitive issues for Japanese organizational contexts. Therefore, the final version of item pool consists of 88 items, with the following content domain distribution: (a) competence, 19 items; (b) benevolence, 9 items; (c) integrity, 15 items; (d) emotional linkage, 14 items; (e) identification, 16 items; (f) depending willingness, 15 items.

\section{Samples and Procedures}

Sample 1 (88 trust items). To empirically explore the factor structure of the 88 items, we conducted a pilot survey in a Chinese university. The immediate supervisor of students in this pilot survey was defined as an individual who is in a superior position in the organizational hierarchy and has authority and responsibility to manage students' daily activities. We collected data of all 88 items from 611 students across six departments of this university. The average age of respondents was 20.3 years $(S D=1.3)$, and $33.4 \%$ were male.

Sample 2 (88 trust items). To reproduce the factor structure of the 88 items, the main survey was conducted for Japanese employees $(n=477)$. Data was collected from all over Japan through a research company. $55.8 \%$ of respondents were male. Their average age was 38.85 years $(S D=6.45)$, average job tenure was 12.92 years $(S D=7.54)$, and the average length of time having worked with the current supervisor was 3.94 years $(S D=4.11)$. In terms of education, $26.6 \%$ had high school degrees, $24.9 \%$ had junior college or vocational degrees, $40.0 \%$ had college degrees, and $8.5 \%$ had graduate degrees. In terms of post, $41.5 \%$ were general employees, $28.9 \%$ and $25.2 \%$ were low and middle level managers, respectively, and others (4.4\%). 


\section{Other Measures in Sample 2}

Altruistic behavior for supervisor was measured using 3 items $(\alpha=.90)$. An example item was "I sometimes sacrifice my own interests to help the supervisor." Proactive behavior was measured with [7]'s 12-item Proactive Behavior Scale (PBS) $(\alpha=.96)$. An example item was "I anticipate changes, and voluntarily propose the solutions in workplace." All variables were measured on 7-point scale, ranging from 1 "strongly disagree" to 7 "strongly agree". The language expression between Chinese and Japanese version questionnaire was checked by a linguist.

\section{Results}

\section{Phase 1: Development of CTS-15 \& ETS-15 in Supervisor}

Validity of Two Higher-Order Constructs. First, using sample 1 as a pilot study, we ran EFA (maximum likelihood method) to check the factor loading pattern of 88 items. In the first estimation (the number of factors was not specified), the initial eigenvalues ( $\%$ of variance) were 44.420 (50.477\%), 6.423 (7.299\%), 2.211 (2.513\%), 1.741 (1.979\%), 1.273 (1.447\%)... The scree criterion indicated two-factor solution. In the second estimation (the number of factors was specified to 2 and oblique rotation was employed), overall the 43-CT items loaded on factor 1 and the 45-ET items loaded on factor 2. Second, to check the reproducibility of this factor loading pattern, we performed the same procedure on the 88 items of sample 2 as a main study. In the first estimation, the initial eigenvalues (\% of variance) were 61.485 (69.869\%), 4.456 (5.063\%), 2.279 (2.590\%), 1.597 (1.815\%), $1.040(1.182 \%) . .$. And, the second estimation showed almost the same factor loading pattern. Thus, for both sample 1 and 2, the 88 items' loading pattern was consistent with hypothesis 1.

To develop scales, we selected items that (1) have theoretically important content; and/or (2) have high loading on the intended factor and low cross-loading on the other for both sample 1 and 2 from the 88 items. This procedure selected 22-CT items and 26-ET items.

Validity of Subdimensional Structure for Each construct. To check the subfactor loading pattern of 22-CT items against hypothesis 2, we ran EFAs (the number of subfactors was specified to 3 and oblique rotation was employed) separately using sample 1 and 2 . As shown in Table 1, the subfactor loading pattern was overall not inconsistent with hypothesis 2 for both sample 1 and 2 . We use the same procedure to check 26-ET items. As Table 2 shows, the subfactor loading pattern was overall not inconsistent with hypothesis 3 for both sample 1 and 2. By selecting items (1) with lower cross-loading on other subfactors and/or (2) with more important content for the corresponding subdimension from these items, 15-item CT Scale (CTS-15) and 15-item ET Scale (ETS-15) in Supervisor were composed. As shown in Table 1 and 2, CTS-15 consists of Q2, Q3, Q4, Q5, Q43 (competence); Q6, Q8, Q09, Q10, Q26 (benevolence); and Q13, Q14, Q30, Q32, Q48 (integrity). ETS-15 is composed of Q65, Q66, Q67, Q68, Q71 (emotional linkage); Q84, Q85, Q87, Q90, Q94 (identification); and Q17, Q50, Q55, Q58, Q61 (depending willingness).

\section{Validation of CTS-15 \& ETS-15 in Supervisor}

The psychometric properties of the six subdimensional scales were assessed using sample 1 and 2 . The coefficient alpha of each subdimensional scale was as follows: (a) competence, $\alpha=.89$ for sample 1, $\alpha=.94$ for sample 2; (b) benevolence, $\alpha=.84$ for sample $1, \alpha=.93$ for sample 2; (c) integrity, $\alpha=.88$ for sample $1, \alpha=.93$ for sample 2; (d) emotional linkage, $\alpha=.92$ for sample $1, \alpha$ $=.95$ for sample 2; (e) identification, $\alpha=.90$ for sample $1, \alpha=.95$ for sample 2; (f) depending willingness, $\alpha=.84$ for sample $1, \alpha=.94$ for sample 2 .

Results of Factorial Validity Analysis. (1) Factorial validity: We used CFAs to evaluate factorial validity with sample 1 and 2 separately $(d f=398)$. For both sample 1 and 2 , the hypothesized second-order factor model showed acceptable fit. Hence, hypothesis 1 3 were supported by both sample 1 and 2, indicating factorial validity. (2) Cross-cultural invariance: We further joint-estimated the hypothesized second-order factor model ( $d f=796)$ to examine its cross-cultural 
invariance. The results $\left(\chi_{(d f)}^{2}=528.652_{(106)}, p=.000\right.$, SRMR $=.051, \mathrm{CFI}=.944, \mathrm{NFI}=.931$, RMSEA= .072) supported the cross-cultural invariance of CTS-15 \& ETS-15 in Supervisor.

Results of Convergent and Discriminant Validity Analysis. We used two criteria to assess convergent validity: the factor loading of each item is (a) significant and (b) greater than .70. For sample 1, all 30 item factor loadings were significant (<.001 level), above .70 (.70 .90). For sample 2 , all 30 item factor loadings were significant (<.001 level), above .70 (.75 .94). Thus, the convergent validity of each subdimension was confirmed.

We used following two analyses to test the discriminant validity among six subdimensions. First, we carried out $\chi^{2}$ difference tests for each pair of the six subdimensions with a series of two-factor confirmatory models. For all pairs, we compared the fixed model (fixing the correlation between one pair of subdimensions to equal 1.00) with the original model (setting this correlation as a free parameter). Discriminant validity is evidenced if the $\chi^{2}$ difference is significant (supporting the original model). For sample 1, all pairs $\left(\chi^{2}\right.$ difference $_{(d f)}$ between $20.205_{(1)}$ and $\left.112.784_{(1)}\right)$ were significant $(p<.001)$. For sample 2, all pairs $\left(\chi^{2}\right.$ difference $(d f)$ between $5.920_{(1)}$ and $\left.56.929_{(1)}\right)$ were significant $(p<.05)$. Thus, the discriminant validity among six subdimensions was confirmed.

Second, we compared the hypothesized second-order factor model consisting of six subdimensions and 30 items (joint-estimation, $d f=796$ ) with nine competing models that each combined two or more subdimensions. The hypothesized model met acceptable level in all fit-indices (SRMR, CTI, NFI, and RMSEA), and was optimal in CFI, NFI, RMSEA, and AIC, indicating the discriminant validity among six subdimensions.

Table 2. 26-ET items' subfactor loading pattern

Table 1. 22-CT items' subfactor loading pattern

\begin{tabular}{|c|c|c|c|c|c|c|}
\hline & \multicolumn{3}{|c|}{ Sample 1} & \multicolumn{3}{|c|}{ Sample 2} \\
\hline & Factor 1 & Factor 2 & Factor 3 & Factor 1 & Factor 2 & Factor 3 \\
\hline Q02 & .04 & .73 & .01 & .76 & .11 & -.02 \\
\hline Q03 & .10 & .64 & .10 & .89 & .06 & -.06 \\
\hline Q04 & .03 & .71 & .10 & .81 & .12 & -.05 \\
\hline Q05 & .09 & .80 & -.05 & .85 & -.09 & .17 \\
\hline Q22 & .25 & .27 & .38 & .78 & .00 & .16 \\
\hline Q43 & .66 & .20 & .02 & .71 & .22 & -.01 \\
\hline Q54 & .58 & .06 & .06 & .71 & .12 & .11 \\
\hline Q06 & -.01 & .70 & .11 & .27 & -.07 & .74 \\
\hline Q07 & .04 & .41 & .34 & .32 & -.13 & .79 \\
\hline Q08 & -.03 & .00 & .67 & -.32 & .59 & .48 \\
\hline Q09 & -.03 & .23 & .62 & -.07 & .30 & .72 \\
\hline Q10 & -.01 & .19 & .66 & .04 & .33 & .60 \\
\hline Q26 & .35 & .19 & .21 & -.02 & .23 & .69 \\
\hline Q13 & .07 & .15 & .62 & .09 & .62 & .19 \\
\hline Q14 & .10 & .17 & .59 & .36 & .57 & .03 \\
\hline Q30 & .52 & -.10 & .43 & .27 & .69 & -.01 \\
\hline Q31 & .62 & -.23 & .45 & .15 & .70 & .09 \\
\hline Q32 & .52 & -.05 & .37 & .05 & .82 & -.02 \\
\hline Q34 & .67 & .11 & -.08 & .15 & .80 & -.01 \\
\hline Q35 & .65 & -.03 & .20 & .16 & .66 & .14 \\
\hline Q48 & .72 & .23 & -.18 & .18 & .56 & .16 \\
\hline Q49 & .82 & .09 & -.06 & .20 & .58 & .21 \\
\hline
\end{tabular}

\begin{tabular}{|c|c|c|c|c|c|c|}
\hline & \multicolumn{3}{|c|}{ Sample 1} & \multicolumn{3}{|c|}{ Sample 2} \\
\hline & Factor 1 & Factor 2 & Factor 3 & Factor 1 & Factor 2 & Factor 3 \\
\hline Q65 & .23 & .19 & .46 & .05 & .05 & .86 \\
\hline Q66 & -.08 & .02 & .95 & .11 & .04 & .81 \\
\hline Q67 & .14 & .15 & .60 & .07 & .45 & .42 \\
\hline Q68 & .03 & .00 & .86 & .05 & .18 & .70 \\
\hline Q71 & .23 & -.07 & .67 & .36 & .02 & .50 \\
\hline Q74 & .51 & .09 & .12 & .27 & .37 & .27 \\
\hline Q76 & .49 & .03 & .33 & .42 & .18 & .35 \\
\hline Q77 & .41 & -.03 & .50 & .38 & .07 & .48 \\
\hline Q83 & .69 & .04 & .13 & .69 & .07 & .19 \\
\hline Q84 & .73 & -.02 & .05 & .57 & .08 & .29 \\
\hline Q85 & .66 & .22 & -.07 & .60 & .18 & .16 \\
\hline Q86 & .75 & -.06 & .15 & .72 & .06 & .17 \\
\hline Q87 & .81 & .02 & .06 & .83 & .04 & .08 \\
\hline Q89 & .74 & .05 & .07 & .72 & .04 & .17 \\
\hline Q90 & .66 & .15 & .05 & .49 & .36 & .11 \\
\hline Q91 & .79 & .13 & -.11 & .60 & .44 & -.09 \\
\hline Q92 & .89 & -.05 & .04 & 1.06 & -.11 & -.05 \\
\hline Q93 & .77 & -.05 & .12 & 1.06 & -.12 & -.09 \\
\hline Q94 & .76 & .07 & -.04 & .73 & .25 & -.06 \\
\hline Q17 & -.09 & .55 & .23 & .16 & .75 & .01 \\
\hline Q19 & -.08 & .69 & .06 & .23 & .65 & -.01 \\
\hline Q37 & -.03 & .81 & .01 & -.09 & 1.01 & -.02 \\
\hline Q50 & .20 & .68 & -.15 & -.03 & .91 & .04 \\
\hline Q55 & .11 & .66 & .02 & -.11 & .95 & .03 \\
\hline Q58 & .11 & .70 & -.03 & .10 & .78 & .09 \\
\hline Q61 & .15 & .44 & .24 & .55 & .13 & .19 \\
\hline
\end{tabular}

Results of Criterion Validity Analysis. We regressed two criterion variables-employees' altruistic behaviors for supervisor and proactive behaviors - on the six subdimensions, with sample 2. As shown in Table 3, among six subdimensions (1) emotional linkage and identification's direct effects on altruistic behavior for supervisor were significant; and (2) only emotional linkage significantly had direct effect on proactive behavior. Thus criterion validity of CTS-15 \& ETS-15 in Supervisor was supported by Japanese employee sample. 
Table 3. Criterion Validity Evidence ( Sample 2)

\begin{tabular}{|c|c|c|c|c|c|c|c|c|}
\hline & \multicolumn{4}{|c|}{ Altruistic behavior } & \multicolumn{4}{|c|}{ Proactive behavior } \\
\hline & $\beta$ & $t$ & $\beta$ & $t$ & $\beta$ & $t$ & $\beta$ & $t$ \\
\hline Gender & -.06 & -1.30 & .02 & .43 & -.02 & -.41 & .03 & .57 \\
\hline Age & -.10 & -1.73 & -.06 & -1.29 & -.05 & -.91 & -.03 & -.56 \\
\hline Education & .09 & 1.85 & .02 & .60 & $.10^{*}$ & 2.10 & .06 & 1.43 \\
\hline Post & $.16^{* * *}$ & 3.21 & .07 & 1.86 & $.20^{* * *}$ & 3.89 & $.15^{* *}$ & 3.01 \\
\hline Tenure with supervisor & .03 & .75 & .02 & .70 & .02 & .50 & .01 & .30 \\
\hline Tenure & -.03 & -.60 & -.01 & -.28 & -.05 & -.92 & -.04 & -.69 \\
\hline Competence & & & -.06 & -1.02 & & & -.11 & -1.45 \\
\hline Benevolence & & & -.09 & -1.21 & & & -.10 & -1.06 \\
\hline Integrity & & & -.06 & -.75 & & & .09 & .85 \\
\hline Emotional linkage & & & $.29 * *$ & 3.05 & & & $.35^{* *}$ & 3.02 \\
\hline Identification & & & $.59 * * *$ & 7.05 & & & .15 & 1.44 \\
\hline Depending willingness & & & -.04 & -.42 & & & -.05 & -.47 \\
\hline$R^{2}(d f)$ & \multicolumn{2}{|c|}{$.04(6 ; 470)$} & \multicolumn{2}{|c|}{$.46(12 ; 464)$} & \multicolumn{2}{|c|}{$.05(6 ; 470)$} & \multicolumn{2}{|c|}{$.17(12 ; 464)$} \\
\hline F statistic & \multicolumn{2}{|c|}{$3.36^{* *}$} & \multicolumn{2}{|c|}{$32.80 * * *$} & \multicolumn{2}{|c|}{$3.90 * * *$} & \multicolumn{2}{|c|}{$8.01^{* * *}$} \\
\hline$\Delta R^{2}(\Delta d f)$ & \multicolumn{4}{|c|}{$.42(6 ; 464)$} & & & \multicolumn{2}{|c|}{$.12(6 ; 464)$} \\
\hline$\Delta F$ & \multicolumn{4}{|c|}{$59.73 * * *$} & & & \multicolumn{2}{|c|}{$11.58^{* * *}$} \\
\hline
\end{tabular}

\section{Discussion}

Our first contribution is to conceptualize the subdimensions of CT \& ET in supervisor, which can explain each subdimension's concrete unique influencing process. The second contribution is to develop CTS-15 \& ETS-15 in Supervisor, which can be distinguishable enough to reliably capture each subdimension's unique relations with other constructs. We assessed the psychometric properties of the six subdimensional scales. First, the reliability coefficients $\alpha$ suggested that each subdimensional scale's items have good internal consistency. Second, the testing results of factorial validity (hypothesis 1 3) and convergent \& discriminant validity supported construct validity of the six subdimensional scales. Third, the results of criterion validity analysis established criterion validity of the six subdimensional scales. These results validated CTS-15 \& ETS-15 in Supervisor.

\section{References}

[1] J. A. Colquitt, M. D. Baer, D. M. Long, \& M. D. K. Halvorsen-Ganepola, Scale indicators of social exchange relationships: A comparison of relative content validity, Journal of Applied Psychology. 99 (2014) 599-618.

[2] Dirks, K. T., Ferrin, D. L., 2002. Trust in leadership: Meta -analytic findings and implications for organizational research, Journal of Applied Psychology, 87, 611-628.

[3] D. McAllister, Affect- and cognition-based trust as foundations for interpersonal cooperation in organizations, Academy of Management Journal. 38, 1995, pp.24-59.

[4] P. M. Blau, Exchange and Power in Social Life, New York: John Wiley, 1964.

[5] R. Cropanzano, M. S. Mitchell, Social exchange theory: An interdisciplinary review, Journal of Management. 31 (2005) 874-900.

[6] D. Rousseau, S. Sitkin, R. Burt, and C. Camerer, Not so different after all: A cross-discipline view of trust, Academy of Management Review. 23(1998)387-392.

[7] R. C. Mayer, J. H. Davis, F. D. Schoorman, An integrative model of organizational trust, Academy of Management Review. 20 (1995)709-734. 